\title{
Ashamed and fused with body image and eating: Binge eating as an avoidance strategy
}

\begin{tabular}{|r|l|}
\hline Journal: & Clinical Psychology \& Psychotherapy \\
\hline Manuscript ID & CPP-1086.R1 \\
\hline Wiley - Manuscript type: & Research Article \\
\hline Complete List of Authors: & $\begin{array}{l}\text { Duarte, Cristiana; University of Coimbra, Cognitive-Behavioural research } \\
\text { Centre, Psychology Department } \\
\text { Pinto-Gouveia, José; Cognitive and Behavioural Centre for Research and } \\
\text { Intervention, Psychology Department } \\
\text { Ferreira, Cláudia; Cognitive and Behavioural Centre for Research and } \\
\text { Intervention, Psychology Department }\end{array}$ \\
\hline Keywords: & $\begin{array}{l}\text { Binge Eating Disorder, Shame, Body image-related cognitive fusion, Eating } \\
\text { concern, Path analysis }\end{array}$ \\
\hline
\end{tabular}


Ashamed and fused with body image and eating: Binge eating as an avoidance strategy

Short title: Ashamed, fused with body image and eating, and binge eating

\author{
Duarte, Cristiana $^{1^{*}}$, Pinto-Gouveia, José ${ }^{1}$ \& Ferreira, Cláudia ${ }^{1}$ \\ ${ }^{1}$ CINEICC - Cognitive and Behavioural Centre for Research and Intervention \\ University of Coimbra, Portugal
}

* Correspondence concerning this article should be addressed to:

Cristiana Duarte

CINEICC, Faculdade de Psicologia e Ciências da Educação, Universidade de Coimbra

Rua do Colégio Novo, Apartado 6153

3001-802 Coimbra, Portugal

E-mail: cristianaoduarte@gmail.com (Cristiana Duarte)

Telephone: $(+351) 239851450$

Fax: (+351) 239851462

\title{
Acknowledgements
}

This research has been supported by the first author (Cristiana Duarte) Ph.D. Grant (SFRH/BD/76858/2011), sponsored by FCT (Portuguese Foundation for Science and Technology). 


\begin{abstract}
Binge Eating Disorder is currently recognized as a severe disorder associated with relevant psychiatric and physical comorbidity, and marked emotional distress. Shame is a specific negative emotion that has been highlighted as central in eating disorders. However, the effect of shame and underlying mechanisms on binge eating symptomatology severity remained unclear. This study examines the role of shame, depressive symptoms, weight and shape concerns and eating concerns, and body image-related cognitive fusion, on binge eating symptomatology severity.

Participated in this study 73 patients with the diagnosis of Binge Eating Disorder (BED), established through a clinical interview - Eating Disorder Examination 17.0D - who completed measures of external shame, body-image related cognitive fusion, depressive symptoms and binge eating symptomatology.

Results revealed positive associations between binge eating severity and depressive symptoms, shame, weight and shape concerns, eating concerns, and body image-related cognitive fusion.
\end{abstract}

A path analysis showed that, when controlling for the effect of depressive symptoms, external shame has a direct effect on binge eating severity, and an indirect effect mediated by increased eating concern and higher levels of body image-related cognitive fusion. Results confirmed the plausibility of the model, which explained $43 \%$ of the severity of binge eating symptoms.

The proposed model suggests that, in BED patients, perceiving that others see the self negatively may be associated with an entanglement with body image-related thoughts and concerns about eating, which may, in turn, fuel binge eating symptoms. Findings have important clinical implications supporting the relevance of addressing shame and associated processes in binge eating. 
Keywords: Binge Eating Disorder; Shame; Body image-related cognitive fusion; Eating concern; Path analysis

\section{Key Practitioner Message:}

- Shame is a significant predictor of symptomatology severity of BED patients.

- Shame significantly impacts binge eating, even controlling for depressive symptoms.

- Shame significantly predicts body image-related cognitive fusion and eating concern.

- Body image-fusion and eating concern mediate the link between shame and binge eating.

- Binge eating may be seen as an avoidance strategy from negative selfevaluations. 


\section{Introduction}

Only recently Binge Eating Disorder (BED) was recognized as a distinct eating disorder diagnosis (American Psychiatric Association, 2013). Nonetheless, binge eating has long been recognized as a severe problem with significant implications for physical and mental health, being linked to the development and maintenance of overweight/obesity and physical and psychiatric comorbidities (e.g., Kessler et al., 2013). According to DSM-5 (American Psychiatric Association, 2013). BED is defined by the engagement in recurrent binge eating episodes characterized by the consumption of a large amount of food, in a discrete period of time, accompanied by a sense of lack of control, in the absence of inappropriate compensatory behaviours. During these episodes at least three of the following are present: one may eat more rapidly than normal; eat until feeling uncomfortably full; eat large amounts of food in the absence of hunger; eat in secrecy because of feeling embarrassed about the behaviour; and feel disgusted with oneself, depressed or very guilty after eating. Binge eating is characterized by marked distress, shame and negative affectivity. Negative affect is therefore a key feature of BED, with research showing that negative emotional states are predictors of binge eating (Leehr et al., 2015), and also play an important role in the maintenance of the disorder (Arnow, Kenardy, \& Agras, 1995; Macht, 2008; Masheb \& Grilo, 2006; Ricca et al., 2009).

Shame entails a particularly important type of negative affect. Shame is a painful self-conscious and socially-focused emotion that derives from evaluations that one is seen negatively by others, as defective, inferior, inadequate and unattractive because of one's shaming personal characteristics (e.g., physical appearance) or behaviours (e.g., eating; Gilbert, 1998, 2000, 2002). This emotion can be focused on the social world, involving evaluations related to the aspects one believes others will 
negatively evaluate, which is referred to as external shame. Nonetheless, these social perceptions can become internalized as negative cognitions and affects about the self. According to Gilbert (1998, 2003, 2007), shame has a defensive function acting as a warning signal that others see and judge the self negatively, which might result in rejection or attack. Shame activates therefore a series of automatic defensive behavioural outputs (e.g., concealment, avoidance, control and excessive selfmonitoring) in order to protect the self from such perceived threats.

Shame has been consistently associated with mental health problems (e.g., Kim, Thibodeau, \& Jorgensen, 2011). Specifically, shame is related with disordered eating attitudes and behaviours and with body image difficulties (e.g., Duarte, PintoGouveia, Ferreira, \& Batista, 2014; Goss \& Allan, 2009; Kelly \& Carter, 2013; Murray, Waller, \& Legg, 2000; Pinto-Gouveia, Ferreira, \& Duarte, 2014). It has been suggested that disordered eating behaviours, such as dieting, may emerge as maladaptive strategies adopted to avoid this threatening emotion and to strive for approval and acceptance by others (e.g., through reaching a socially valued thin physical appearance; Gilbert, 2002; Goss \& Allan, 2009; Goss \& Gilbert, 2002). Binge eating may also be conceptualized as a maladaptive strategy to avoid or escape from disturbing thoughts or negative emotions (Arnow et al., 1995; Goldfield, Adamo, Rutherford, \& Legg, 2008; Heatherton \& Baumeister, 1991; Leehr et al., 2015). However, these behaviours paradoxically increase negative affect and negative self-evaluations, being associated with increased shame, guilt and criticism (Duarte, Pinto-Gouveia, \& Ferreira, 2014; Goss \& Gilbert, 2002; Hayaki, Friedman, \& Brownell, 2002; Jambekar, Masheb, \& Grilo, 2003). Thus, such behaviours seem to fuel a maladaptive self-sustained cycle in which complex emotion regulation processes seem to be implicated. 
A particularly important process operating in this cycle may be cognitive fusion, defined as the degree to which one's internal experiences are perceived as trustworthy presentations of reality and acted upon, instead of experienced as transitory and subjective mental events (Gillanders, Bolderston, Bond, Dempster, \& Flaxman, 2014; Luoma \& Hayes, 2003). In fact, it has been suggested that being fused and dominated by thoughts, tends to lead to avoidance-driven behavioural consequences that in themselves may be damaging and increase personal distress and suffering (Barnes-Holmes \& Dymond, 2001; Hayes, 2004; Hayes, Luoma, Bond, Masuda, \& Lillis, 2006). Furthermore, cognitive fusion has been related to difficulties in changing one's behaviors, even when that change would be desirable, beneficial and increase well-being (e.g., regulation of eating behaviour; Forman \& Butryn, 2015; S. Hayes, Strosahl, \& Wilson, 1999).

Research showed that cognitive fusion, especially regarding unwanted and disturbing thoughts or emotions related to body image, has an important effect in eating psychopathology (Ferreira, Trindade, Duarte, \& Pinto-Gouveia, 2014; Merwin \& Wilson, 2009; Trindade \& Ferreira, 2014). In particular, a recent study has shown that body image-related cognitive fusion mediates the association between body image negative experiences, such as self-evaluations of inferiority, and eating psychopathology (Ferreira, Palmeira, \& Trindade, 2014). Nonetheless, the specific impact of cognitive fusion (namely focused on body image) in patients with BED regarding the severity of the disorder was never examined.

Moreover, in contrast to the eating disorder diagnoses of Bulimia Nervosa and Anorexia Nervosa, the diagnosis of BED does not include a criterion reflecting a disturbance in body image, although there is some evidence showing that body image is an important dimension for BED patients (Grilo, Masheb, \& White, 2010; Masheb 
\& Grilo, 2000). Thus, whilst the other formal eating disorder diagnoses are recognized as being characterized by disturbances in both eating behaviour and body image, the dimension of body image in BED and the way it may be related to maladaptive eating attitudes (involving concerns about losing control about eating, eating in secrecy to avoid the scrutiny from others, and guilt about eating), are still little explored. Furthermore, the impact of perceptions of the self being negatively evaluated or derogated by others, and the processes through which they influence the severity of the disorder, remain unclear.

The current study aimed at examining the association between shame, depressive symptoms, eating psychopathology, body mass index, body image-related cognitive fusion, and binge eating severity in patients with BED. In particular, this study presents and tests a parsimonious model explaining the severity of binge eating symptoms in this clinical condition. This model investigates the effect of the specific negative emotion of shame on both pathological concerns about eating and the entanglement with thoughts about body image (accounting for the effect of body mass index), which were hypothesised as mediator mechanisms explaining the severity of binge eating symptomatology.

\section{Method}

\section{Participants}

Seventy-three women meeting the DSM-5 criteria (American Psychiatric Association, 2013) for BED participated in this study. The diagnoses were established through the interview Eating Disorders Examination 17.0D (Fairburn, Cooper, \& O'Connor, 2008). Participants had between 20 and 59 years old, $(M=38.10 ; S D=$ $10.88)$ and 4 to 19 years of education $(M=13.74 ; S D=3.80)$, with the majority being 
married/living with a partner (58.9\%). Participants' BMI ranged from 20.83 to 50.32, with $15.1 \%$ presenting normal weight $(18.5<$ BMI $<24.99), 12.3 \%$ being overweight $(25<\mathrm{BMI}<29.99), 30.1 \%$ presenting Class I Obesity $(30<\mathrm{BMI}<34.99), 15.1 \%$ presenting Class II Obesity $(\mathrm{BMI}>35<39.99)$, and $27.4 \%$ presenting class III Obesity $(\mathrm{BMI} \geq 40)$.

\section{Measures}

Body Mass Index (BMI). Participants' BMI was calculated by dividing the weight (in $\mathrm{kg}$ ) by height squared (in $\mathrm{m}$ ) collected using standard calibrated instruments.

Eating Disorder Examination 17.0D (EDE 17.0D; Fairburn et al., 2008; Ferreira, Pinto-Gouveia, \& Duarte, 2010). The EDE is an investigator-based clinical interview that provides a comprehensive assessment of the frequency and severity of key behavioural and psychological aspects of eating disorders. It comprises four subscales: Restraint, Eating Concern, Weight Concern and Shape Concern. A global score may be obtained by calculating the mean of the subscales' scores. Furthermore, the EDE 17.0D allows for a thorough assessment of the diagnostic criteria and the specific psychopathology of patients with BED, according to the DSM-5 criteria. Research has shown that EDE presents high values of internal consistency (.80 in the current study), discriminant and concurrent validity, and test-retest reliability (for a review see (Fairburn, 2008).

Binge Eating Scale (BES; Duarte, Pinto-Gouveia, \& Ferreira, 2014; Gormally, Black, Daston, \& Rardin, 1982). This scale comprises 16 items assessing the severity of binge eating symptomatology, including the emotional and cognitive aspects and 
behavioural manifestations of binge eating. Each item comprises three or four statements regarding which participants are asked to select the one that best describes their experience. Each option represents a rating of severity that ranges from 0 (no difficulties with binge eating) to 3 (severe problems with binge eating). Higher scores indicate higher binge eating severity. The Cronbach's alpha of the scale in the current study was .81 .

Depression Anxiety and Stress Scales (DASS21; Apóstolo, Mendes, \& Azeredo, 2006; Lovibond \& Lovibond, 1995). This scale includes 21 items measuring levels of depression, anxiety and stress symptoms. Respondents are asked to indicate the frequency in which they experienced each symptom over the past week using a 5point Likert scale $(0=$ 'Did not apply to me at all' to $4=$ 'Applied to me very much, or most of the time'). Higher results indicate higher levels of emotional distress. In the current study, depressive symptomatology was assessed through the depression subscale. DASS21 presents good psychometric properties; the Cronbach's alpha for the depression subscale in the current study was .90 .

Other as Shamer Scale (OAS; Goss, Gilbert, \& Allan, 1994); Matos, PintoGouveia, \& Duarte, 2011). This scale includes 18 items measuring external shame. Participants are asked to rate the items on a 5 -point Likert scale $(0=$ 'Never' to $4=$ 'Almost always') according to the frequency they make certain evaluations about how others negatively judge, look down or criticize them. In the original study the scale showed good reliability, with a Cronbach's alpha of .92 (Goss et al., 1994). In the present study we obtained a value of .95 .

Cognitive Fusion Questionnaire-Body Image (CFQ-BI; Ferreira, Trindade, et al., 2014). This questionnaire was based on the original Cognitive Fusion Questionnaire (Gillanders et al., 2014) and includes 10 items measuring cognitive 
fusion related to body image. Participants are asked to rate the extent in which each statement (e.g., 'My thoughts relating to my body image cause me great distress or emotional pain') is true regarding their own experience, using a 7-point Likert scale (1 $=$ 'Never true' to $7=$ 'Always true'). This scale presents good internal consistency, retest reliability, discriminant, convergent and divergent validities (with a Cronbach's alpha of .96 in the current study; Ferreira, Trindade, et al., 2014).

\section{Procedure}

Participants were treatment-seeking adults who met DSM-5 diagnosis criteria for BED, recruited at the Hospitalary Centre of the University of Coimbra, after the approval of the respective Ethics Committee. All the diagnostic and assessment procedures were performed by the two of the researchers, who are clinical psychologists with considerable experience in the assessment and treatment of eating disorders. The procedure and aims of the study were fully explained to the potential participants, and those wanting to take part in the study provided their written informed consent. Were included in the study participants who met the following criteria: i) women with ages between 18 and 60 years; ii) diagnosis of current BED, assessed through the EDE 17.0D. The exclusion criteria were as follows: i) current comorbid severe mental disorders (e.g., bipolar disorder, severe major depression, schizophrenia, psychotic substance and alcohol abuse) as established by a screening clinical interview based on criteria from DSM-5 (American Psychiatric Association, 2013); ii) current pregnancy; iii) medical or endocrine disorders (e.g., diabetes); vi) illiteracy and mental retardation. Participants who met the required criteria answered the self-report measures. 
Analytic strategy

Descriptives and correlational analyses were conducted using the software SPSS (v.21 SPSS; Armonk, NY: IBM Corp.). Product-moment Pearson Correlation analyses were conducted to examine the correlations between binge eating severity, depressive symptoms, external shame, eating psychopathology attitudinal and behavioural symptoms, and body image-related cognitive fusion and BMI (Cohen, Cohen, West, \& Aiken, 2003).

A path analysis, examined using the software AMOS 21 (Analysis of Momentary Structure, SPSS Inc. Chicago, IL), was conducted to estimate the associations between the study variables hypothesized in the model (Figure 1). Path analysis is a specific type of Structural Equation Modelling (SEM) used to simultaneously examine structural direct and indirect associations between multiple exogenous and endogenous variables, while controlling for error (Kline, 2005). The current study examined whether the association between external shame and depressive symptoms (exogenous variables) and binge eating severity (endogenous variable) would be mediated by body image-related cognitive fusion and concerns about eating, having BMI as a covariate (endogenous mediator variables). The Maximum Likelihood estimation method was selected and following goodness of fit indices were used to evaluate the plausibility of the model: Chi-square $\left(\chi^{2}\right)$, Tucker Lewis Index (TLI), Comparative Fit Index (CFI), Normed Fit Index (NFI) and RootMean Square Error of Approximation (RMSEA). The significance of the direct, indirect and total effects was assessed by Chi-Square tests and the significance of the mediational paths were further confirmed through the Bootstrap resampling method, with 2000 Bootstrap samples and 95\% bias-corrected confidence intervals (CI): 
effects were considered significant $(p<.050)$ if zero was not included in the interval between the lower and the upper limits of the CI (Kline, 2005).

Effects with $p<.050$ were considered statistically significant.

\section{Results}

\section{Descriptives}

Results (Table 1) indicated that EDE scores were above the normative cut-off point for clinical significance (Fairburn, 2008; Fairburn \& Beglin, 1994). Also, participants reported 4 to 30 objective binge-eating episode per month, over the last three months.

Participants' scores for BES corresponded to severe levels of binge eating. In particular, $5.5 \%$ of the participants presented low scores of binge eating; $27.4 \%$ presented moderate binge eating; and $67.1 \%$ reported severe binge eating. The scores of the other study variables were above to those obtained in previous studies with nonclinical samples and similar to what was found in eating disorders samples (Duarte et al., 2014; Ferreira, Pinto-Gouveia, \& Duarte, 2013; Trindade \& Ferreira, 2014).

\section{Correlations between the study measures}

Product-moment Pearson correlation coefficients (two-tailed) are presented in Table 1. Results indicated that binge eating severity, as measured by the BES, was positively and moderately associated with the EDE subscales eating concern, shape concern and weight concern, and with the frequency of objective binge eating 
episodes. A stronger association was found between the BES and the EDE total score. Also, binge eating was positively and moderately associated with depressive symptoms. Furthermore, binge eating severity presented a strong positive association with external shame and with body image-related cognitive fusion. No significant associations were found between the BES and BMI and eating restraint (EDE).

Regarding external shame, results indicated a positive association with depressive symptoms, eating and weight concerns, and with the global EDE score. Also, external shame was positively and moderately correlated with body imagerelated cognitive fusion. Body image-related cognitive fusion, in turn, showed a positive albeit weak association with BMI, and a moderate association with depressive symptoms and eating concern EDE subscale. A stronger association was found between cognitive fusion and shape and weight concerns and the EDE total score.

Insert Table 1 around here

\section{Path analysis}

Univariate and multivariate normality was confirmed through the coefficients of Skewness and Kurtosis, which confirmed that there was no serious violation of normal distribution, with values of Skewness ranging from -.14 to -.82, and Kurtosis values between .03 and -.97 (Kline, 2005). Also there was no indication of multicollinearity.

The tested model accounted for $44 \%$ of the variance of binge eating severity. An initial analysis of the tested model indicated that the effects of depression on eating concern $\left(b_{\text {depression }}=.02 ; \mathrm{SE} b=.03 ; \mathrm{Z}=.69 ; p=.489 ; \beta=.09\right)$, on body imagerelated cognitive fusion $\left(b_{\text {depression }}=.05 ; \mathrm{SE} b=.03 ; \mathrm{Z}=1.44 ; p=.150 ; \beta=.18\right)$, and 
binge eating $\left(b_{\text {depression }}=-.06 ; \mathrm{SE} b=.15 . ; \mathrm{Z}=-.38 ; p=.702 ; \beta=-.04\right)$, the effect of external shame on BMI $\left(b_{\mathrm{OAS}}=-.03 ; \mathrm{SE} b=.07 ; \mathrm{Z}=-.53 ; p=.593 ; \beta=-.07\right)$, and the effect of BMI on binge eating $\left(b_{\mathrm{BMI}}=.08 ; \mathrm{SE} b=.09 ; \mathrm{Z}=.88 ; p=.380 ; \beta=.08\right)$ were nonsignificant and were therefore eliminated. The recalculated model predicting binge eating severity, revealed that all path coefficients were statistically significant, and presented an excellent model fit $\left[\chi_{(5)}^{2}=3.11 p=.684 ; \mathrm{TLI}=1.06 ; \mathrm{CFI}=1.00 ; \mathrm{NFI}=\right.$ $.97 ; \operatorname{RMSEA}=.00(p=.760)$.

Results indicated that external shame accounted for $22 \%$ of body imagerelated cognitive fusion, with a direct effect of $.47\left(b_{\mathrm{OAS}}=.04 ; \mathrm{SE}=.01 ; \mathrm{Z}=4.56 ; p<\right.$ .001 ); also, it accounted for $10 \%$ of eating concern variance with a direct effect of .31 $\left(b_{\mathrm{OAS}}=.03 ; \mathrm{SE} b=.01 ; Z=2.80 ; p=.005\right)$. Depressive symptoms accounted for $7 \%$ of BMI variance $\left(b_{\text {depression }}=.37 ; \mathrm{SE} b=.16 ; Z=2.36 ; p=.018 ; \beta=.26\right)$, but no significant associations were verified between BMI and the mediators.

Body image-related cognitive fusion directly predicted BES, with a direct effect of $.33\left(b_{\mathrm{CFQ}-\mathrm{BI}}=1.58 ; \mathrm{SE} b=.50 ; Z=3.16 ; p=.002\right)$, while eating concern had a direct effect of $.32\left(b_{\text {EatConcern }}=1.75 ; \mathrm{SE}=.53 ; Z=3.33 ; p<.001\right)$ on BES. External shame presented a total effect of .46 on BES, with a direct effect of $.20\left(b_{\mathrm{OAS}}=.09\right.$; $\mathrm{SE}=.05 ; Z=2.00 ; p=.045)$ and an indirect effect (.26) mediated by increased body image-related cognitive fusion and eating concern. The examined effects were significant $(p<.001)$ according to the Bootstrap resampling method. Specifically, the estimate of the indirect effect of external shame on binge eating framed by a CI of $.95 \%$ revealed an effect significantly different from zero $(\mathrm{CI}=.12, .42 ; p=.001)$. Figure 1 presents the model with standardized estimates.

Insert Figure 1 around here 


\section{Discussion}

This study evaluated the association between shame, depressive symptoms, cognitive fusion, eating disorder symptomatology, and binge eating severity. In particular, this study presents a model examining the effect of shame on binge eating symptoms' severity and the mediator role of body image cognitive fusion and eating concern on this association, in patients with BED.

Results corroborated prior research showing that BED is associated with excess weight and obesity, but that this disorder is also present in women with normal weight (Kessler et al., 2013). In fact, in the current sample, binge eating symptomatology severity was not associated with BMI, which is in accordance with prior research (Ricca et al., 2009).

Findings indicated that the severity of binge eating symptomatology, as measured by the BES, was associated with higher severity of eating psychopathology, especially concerns about eating. Furthermore, findings corroborated prior research regarding the association between binge eating symptomatology severity and increased depressive symptoms and shame (Duarte et al., 2014) but extended them to a clinical sample further showing that cognitive fusion related with body image is an important correlate of binge eating symptoms. Also, in these patients, this process of cognitive fusion, that is, feeling caught in thoughts about physical appearance, was positively associated with perceiving oneself as being seen negatively by others (e.g., as defective, inferior, unattractive in the eyes of others).

The path analysis findings revealed that the model examined to understand the relationship between shame and binge eating severity is plausible, explaining a total of $44 \%$ of binge eating severity variance. This model proposed that in patients with BED feeling that others look down on the self directly predicted higher severity of 
binge eating symptoms, even when controlling for the effect of depression. These results extend prior evidence on the association between shame and eating psychopathology (Ferreira et al., 2013; Pinto-Gouveia et al., 2014), especially bulimic symptomatology (Hayaki et al., 2002). In fact, results corroborate that negative affect has an important role in binge eating (Leehr et al., 2015) but extend existent considerations (Duarte et al., 2014) demonstrating that shame is a specific negative emotion important for the understanding of binge eating symptomatology.

Nonetheless, our findings also suggest that the relationship between shame and binge eating is complex and influenced by different mechanisms. Indeed, results indicated that the effect of this negative emotional experience of shame on binge eating is partially influenced by the tendency to become fused with thoughts about body image (even when accounting for the effect of BMI) and overly concerned about eating (e.g., with fears of losing control over eating, the perceived need to conceal eating behaviour from others and feelings of guilt about eating). The model proposed in the current study suggests that binge eating may be understood as a strategy to avoid, escape or distract oneself from aversive internal experiences, such as the threat of feeling inferior, ostracized or rejected by others. It is likely that in BED patients feeling ashamed is linked to physical appearance and eating dimensions. As cognitive fusion fuels experiential avoidance (Gillanders et al., 2014; Hayes et al., 1999), it seems possible that binge eating emerges as a consequence of being fused with thoughts with body image and over concerned about eating, even that, in the long term, binge eating may cause greater distress and the patients find themselves in a perpetual cycle of shame and deregulated eating. This has important clinical implications suggesting the relevance of interventions for BED that target shame by helping people to disengage from negative self-evaluations, and that promote a 
willingness to turn towards and accept negative internal experiences, rather than turning away from them through avoidance strategies that create greater suffering (e.g., Compassion Focused Therapy and Acceptance and Commitment Therapy; Forman \& Butryn, 2015; Gilbert, 2005; Goss \& Allan, 2010; Hill, Masuda, Melcher, Morgan, \& Twohig, 2014).

These findings cannot however be understood without taking into account important limitations. This survey was cross-sectional impairing conclusions regarding causality and the directionality of the tested associations. Also, eating disorders are complex and multidetermined conditions and thus the model examined in this study was intentionally limited. Thus, future studies using larger samples should investigate the role of other variables influencing the severity of binge eating in patients with BED. For instance, future research should focus on the role that other dimensions of cognitive fusion may play on the studied associations, such as becoming fused with thoughts and concerns about eating. This model should also be investigated considering the specificity of eating psychopathology in male patients with BED, testing whether shame and body image-related variables remain salient or if other features are more pertinent in this population.

Nevertheless, this study presents a novel model that proposes the pathways through which shame may impact on the symptomatology of patients with BED, which open new avenues for research and carries important clinical implications. 


\section{References}

American Psychiatric Association, A. P. A. (2013). Diagnostic and statistical manual of mental disorders : DSM-5. Arlington, VA: American Psychiatric Publishing.

Apóstolo, J., Mendes, A., \& Azeredo, Z. (2006). Adaptation to Portuguese of the Depression, Anxiety and Stress Scales (DASS). Revista Latino-Americana de Enfermagem, 14(6), 863-871.

Arnow, B., Kenardy, J., \& Agras, W. S. (1995). The Emotional Eating Scale: the development of a measure to assess coping with negative affect by eating. International Journal of Eating Disorders, 18(1), 79-90. doi:10.1002/1098108X(199507)18:1\%3C79::AID-EAT2260180109\%3E3.0.CO;2-V

Barnes-Holmes, D., C., H. S., \& Dymond, S. (2001). Self and self-directed rules. In S. Hayes, D. Barnes-Holmes, \& B. Roche (Eds.), Relational frame theory. A post Skinnerian account of human language and cognition (pp. 119-139). New York: Plenum Press.

Cohen, J., Cohen, P., West, S., \& Aiken, L. (2003). Applied multiple regression/correlation analysis for the behavioural sciences (3th ed.). New Jersey: Lawrence Erlbaum Associates.

Duarte, C., Pinto-Gouveia, J., \& Ferreira, C. (2014). Escaping from body image shame and harsh self-criticism: Exploration of underlying mechanisms of binge eating. Eating Behaviors, 15(4), 638-643. doi:10.1016/j.eatbeh.2014.08.025

Duarte, C., Pinto-Gouveia, J., \& Ferreira, C. (2014). Expanding binge eating assessment: Validity and screening value of the Binge Eating Scale in women from the general population. Manuscript submitted for publication. 
Duarte, C., Pinto-Gouveia, J., Ferreira, C., \& Batista, D. (2014). Body image as a source of shame: A new measure for the assessment of the multifaceted nature of body image shame. Clinical Psychology \& Psychotherapy, Advance online publication. doi:10.1002/cpp.1925

Fairburn, C. (2008). Cognitive behavior therapy and eating disorders New York: Guilford Press.

Fairburn, C., \& Beglin, S. (1994). Assessment of eating disorders: Interview or selfreport questionnaire? International Journal of Eating Disorders, 16(4), 363370. doi:10.1002/1098-108X(199412)16:4<363::AIDEAT2260160405>3.0.CO;2-\#

Fairburn, C., Cooper, Z., \& O’Connor, M. (2008). Eating Disorder Examination (Edition 16.0D). In C. Fairburn (Ed.), Cognitive behavior therapy and eating disorders (pp. 265-308). New York: Guilford Press.

Ferreira, C., Palmeira, L., \& Trindade, I. (2014). Turning eating psychopathology risk factors into action. The pervasive effect of body image-related cognitive fusion. Appetite, 80, 137-142. doi:10.1016/j.appet.201405.019

Ferreira, C., Pinto-Gouveia, J., \& Duarte, C. (2010). Dados psicométricos da versão portuguesa da Eating Disorder Examination 16.OD [Psychometric data of the Portuguese version of the Eating Disorder Examination 16.OD]. Manuscript in preparation.

Ferreira, C., Pinto-Gouveia, J., \& Duarte, C. (2013). Self-compassion in the face of shame and body image dissatisfaction: Implications for eating disorders. Eating Behaviors, 14(2), 207-210. doi:10.1016/j.eatbeh.2013.01.005

Ferreira, C., Trindade, I. A., Duarte, C., \& Pinto-Gouveia, J. (2014). Getting entangled with body image. Development and validation of a new measure. 
Psychology and Psychotherapy: Theory research and practice. doi:10.1111/papt.12047

Forman, E. M., \& Butryn, M. (2015). A new look at the science of weight control: How acceptance and commitment strategies can address the challange of selfregulation. Appetite, 84, 171-180. doi:10.1016/j.appet.2014.10.004

Gilbert, P. (1998). What is shame? Some core issues and controversies. In P. Gilbert \& B. Andrews (Eds.), Shame: Interpersonal behaviour, psychopathology and culture (pp. 3-36). New York: Oxford University Press.

Gilbert, P. (2000). The relationship of shame, social anxiety and depression: The role of the evaluation of social rank. Clinical Psychology \& Psychotherapy, 7(2000), 174-189. doi:10.1002/1099-0879(200007)7:3<174::AIDCPP236>3.0.CO;2-U

Gilbert, P. (2002). Body shame: A biopsychosocial conceptualisation and overview with treatment implications. In P. Gilbert \& J. Miles (Eds.), Body shame: Conceptualisation, research and treatment (pp. 3-54). New York: Brunner Routledge.

Gilbert, P. (2003). Evolution, social roles and the differences in shame and guilt. Social Research: An International Quarterly, 70, 1205-1230.

Gilbert, P. (2005). Compassion: Conceptualisations, research and use in psychotherapy. New York: Routledge.

Gilbert, P. (2007). The evolution of shame as a marker for relationship security. In J. Tracy, R. Robins, \& J. Tangney (Eds.), The Self-Conscious Emotions: Theory and research (pp. 283-309). New York: Guilford. 
Gillanders, D., Bolderston, H., Bond, F. W., Dempster, M., \& Flaxman, P. (2014). The development and initial validation of the cognitive fusion questionnaire. Behavior Therapy, 45(1), 83-101. doi:10.1016/j.beth.2013.09.001

Goldfield, G. S., Adamo, K. B., Rutherford, J., \& Legg, C. (2008). Stress and the relative reinforcing value of food in female binge eaters. Physiol Behav, 93(3), 579-587. doi:10.1016/j.physbeh.2007.10.022

Gormally, J., Black, S., Daston, S., \& Rardin, D. (1982). The assessment of binge eating severity among obese persons. Addictive behaviors, 7(1), 47-55. doi:10.1016/0306-4603(82)90024-7

Goss, K., \& Allan, S. (2009). Shame, pride and eating disorders. Clinical Psychology \& Psychotherapy, 16, 303-316. doi:10.1521/ijct.2010.3.2.141

Goss, K., \& Allan, S. (2010). Compassion Focused Therapy for eating disorders. International Journal of Cognitive Therapy, 3(2), 141-158. doi:10.1521/ijct.2010.3.2.141

Goss, K., \& Gilbert, P. (2002). Eating disorders, shame and pride: A cognitivebehavioural functional analysis. In P. Gilbert \& J. Miles (Eds.), Body shame: Conceptualisation, research and treatment (pp. 219-255). New York: Brunner Routledge.

Goss, K., Gilbert, P., \& Allan, S. (1994). An exploration of shame measures: I: The 'other as shamer'scale. Personality and Individual Differences, 17, 713-717. doi:10.1016/0191-8869(94)90149-X

Grilo, C., Masheb, R., \& White, M. A. (2010). Significance of overvaluation of shape/weight in Binge Eating Disorder: Comparative study with overweight and bulimia nervosa. Obesity, 18(3), 499-504. doi:10.1038/oby.2009.280 
Hayaki, J., Friedman, M., \& Brownell, K. (2002). Shame and severity of bulimic symptoms. Eating Behaviors, 3, 73-83. doi:10.1016/S1471-0153(01)00046-0

Hayes, S. (2004). Acceptance and commitment therapy, relational frame theory, and the third wave of behavioral and cognitive therapies. Behavior Therapy, 35(4), 639-665. doi:10.1016/s0005-7894(04)80013-3

Hayes, S., Strosahl, K. D., \& Wilson, K. (1999). Acceptance and Commitment Therapy: An experiential approach to behavior change. New York: Guilford Press.

Hayes, S. C., Luoma, J. B., Bond, F. W., Masuda, A., \& Lillis, J. (2006). Behaviour Research and Therapy. Behaviour Research and Therapy, 44, 1-25. doi:10.1016/j.brat.2005.06.006

Heatherton, T., \& Baumeister, R. (1991). Binge eating as escape from self-awareness. Psychological Bulletin, 110(1), 86-108. doi:10.1037/0033-2909.110.1.86

Hill, M., Masuda, A., Melcher, H., Morgan, J., \& Twohig, M. (2014). Acceptance and commitment therapy for women diagnosed with binge eating disorder: A caseseries study. Cognitive and Behavioral Practice. doi:10.1016/j.cbpra.2014.02.005

Jambekar, S., Masheb, R., \& Grilo, C. (2003). Gender differences in shame in patients with Binge-Eating Disorder. Obesity, 11(4), 571-577.

doi:10.1038/oby.2003.80

Kelly, A. C., \& Carter, J. C. (2013). Why self-critical patients present with more severe eating disorder pathology: The mediating role of shame. British Journal of Clinical Psychology, 52, 148-161. doi:10.1111/bjc.12006

Kessler, R., Berglund, P., Chiu, W.-., Deitz, A., Hudson, J., Shahly, V., . . . Xavier, M. (2013). The prevalence and correlates of Binge Eating Disorder in the 
World Health Organization World Mental Health Surveys. Biological

Psychiatry, 73(9), 904-914. doi:10.1016/j.biopsych.2012.11.020

Kim, S., Thibodeau, R., \& Jorgensen, R. (2011). Shame, guilt, and depressive symptoms: A meta-analytic review. Psychological Bulletin, 137(1), 68-96. doi:10.1037/a0021466

Kline, R. B. (2005). Principles and practice of structural equation modeling (2nd ed.). New York: The Guilford Press.

Leehr, E., Krohmer, K., Schag, K., Dresler, T., Zipfel, S., \& Giel, K. (2015). Emotion regulation model in binge eating disorder and obesity - A systematic review. Neuroscience and Behavioral Reviews, 49, 125-134. doi:10.1016/j.neurobirev.2014.12.008

Lovibond, S., \& Lovibond, P. (1995). Manual for the Depression Anxiety Stress Scales (2nd ed.). Sydney: Psychology Foundation.

Luoma, J., \& Hayes, S. C. I. W. T. D., J. E. Fisher, \& S. C. Hayes, (Eds.), Empirically supported techniques for cognitive behavior therapy: A step by step guide for clinicians. New York: Wiley. (2003). Cognitive defusion. In W. Donohue, J. Fisher, \& S. Hayes (Eds.), Empirically supported techniques for cognitive behavior therapy: A step by step guide for clinicians. New York: Wiley.

Macht, M. (2008). How emotions affect eating: A five-way model. Appetite, 50(1), 111. doi:10.1016/j.appet.2007.07.002

Masheb, R., \& Grilo, C. (2000). Binge eating disoder: A need for additional diagnostic criteria. Compr Psychiatry, 41(3), 159-162. doi:10.1016/S0010$440 X(00) 90041-5$

Masheb, R., \& Grilo, C. (2006). Emotional overeating and its associations with eating disorder psychopathology among overweight patients with Binge eating 
disorder. International Journal of Eating Disorders, 39, 141-146. doi:10.1002/eat.20221

Matos, M., Pinto-Gouveia, J., \& Duarte, C. (2011). Other as shamer: Versão Portuguesa e propriedades psicométricas de uma medida de vergonha externa [Other as shamer: Portuguese version and psychometric properties of a measure of external shame]. Manuscript submitted for publication.

Merwin, R., \& Wilson, K. (2009). Understanding and treating eating disorders. An ACT perspective. In J. Blackledge, J. Ciarrochi, \& P. Deane (Eds.), Acceptance and Commitment Therapy. Contemporary theory, research, and practice (pp. 87-117). Austraia: Australian Academic Press.

Murray, C., Waller, G., \& Legg, C. (2000). Family dysfunction and bulimic psychopathology: The mediating role of shame. International Journal of Eating Disorders, 28(1), 84-89. doi: 10.1002/(SICI)1098108X(200007)28:1<84::AID-EAT10>3.0.CO;2-R

Pinto-Gouveia, J., Ferreira, C., \& Duarte, C. (2014). Thinness in the pursuit for social safeness: An integrative model of social rank mentality to explain eating psychopathology. Clinical Psychology \& Psychotherapy, 21(2), 154-165. doi:10.1002/cpp. 1820

Ricca, V., Castellini, G., Lo Sauro, C., Ravaldi, C., Lapi, F., Mannucci, E., .. . Faravelli, C. (2009). Correlations between binge eating and emotional eating in a sample of overweight subjects. Appetite, 53(3), 418-421. doi:10.1016/j.appet.2009.07.008

Trindade, I., \& Ferreira, C. (2014). The impact of body image-related cognitve fusion on eating psychopathology. Eating Behaviors, 15(1), 72-75.

doi:10.1016/j.eatbeh.2013.10.014 
Table 1. Descriptive statistics and product-moment Pearson correlation coefficients between the study measures $(N=73)$

$S D$

1_BES $\quad 29.55 \quad 7.08 \quad 1$

2_BMI $\quad .18$

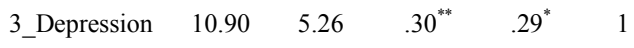

4_EDE_Restra $2.98 \quad 1.16 \quad .14 \quad-.07 \quad 06 \quad 1$

int

5_EDE_Eating $2.60 \quad 1.31 \quad .51^{* * *} \quad .02 \quad 14^{*} \quad .32^{* * *} \quad 1$

Concern

6_EDE_Shape $4.86 \quad 1.06 \quad .33^{* * *} \quad .45^{* * *} \quad .27^{*} \quad .05 \quad .39^{* * *} \quad 1$

Concern

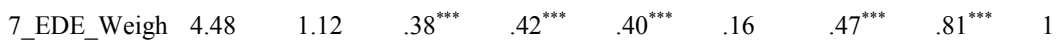

t Concern

8_EDE Total $\quad 3.73 \quad 0.84 \quad .48^{* * *} \quad .27^{*} \quad .33^{* * *} \quad .54^{* * *} \quad .78^{* * *} \quad .75^{* * *} \quad .83^{* * *} \quad 1$

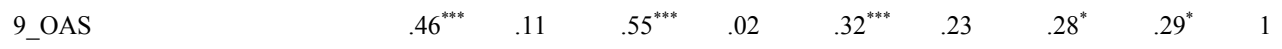

10_CFQ BI

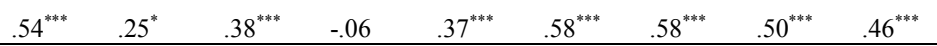

Note: $* p<.050 ; * * * p<.001$

BES = Binge Eating Scale; BMI = Body Mass Index; Depression = DASS21 subscale; EDE = Eating Disorder Examination; OAS $=$ Other as Shamer Scale; CFQ-BI = Cognitive Fusion Questionnaire-Body Image 


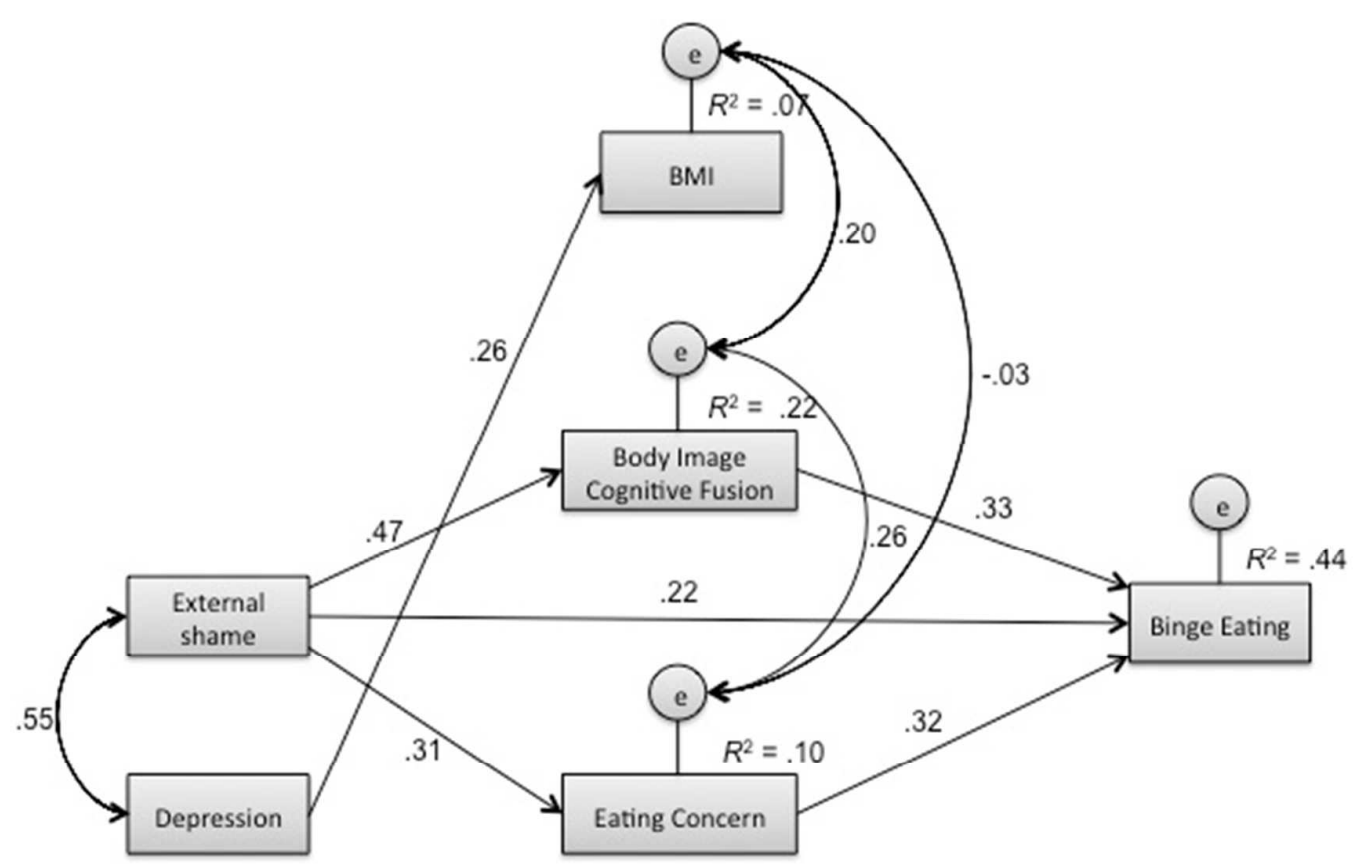

Figure 1. Path model on the association between external shame and depressive symptoms, and binge eating symptomatology severity, mediated by body image cognitive-fusion and eating concerns, accounting for the effect of body mass index, with standardized estimates and square multiple correlations $(N=73)$ 
Path model on the association between external shame and depressive symptoms, and binge eating symptomatology severity, mediated by body image cognitive-fusion and eating concerns, accounting for the effect of body mass index, with standardized estimates and square multiple correlations $(\mathrm{N}=73)$ $254 \times 190 \mathrm{~mm}$ (72 x 72 DPI) 